\title{
Contemporary Mourning and Digital Estates Angela Galvan
}

User experience and design, law, and philosophy have discussed the fate of individuals' web and social medial presence after death for some time. ${ }^{1}$ This residual, postmortem presence is our digital estate. As the theoretical implications of digital estates continue to gain attention, librarians and information professionals of all kinds will engage practical questions about this topic from survivors.

This chapter has three functional purposes. First, to situate the digital estate within the current cultural experience of death and mourning in the United States; second, to offer introductory guidance for information professionals to proactively engage community members on this topic before one's own death; and third, to assist information professionals as bereaved patrons try to make meaning from the digital estate of the deceased.

\section{Contemporary Mourning}

Physical death is for the most part sequestered or separated from our everyday experience in the United States. Our "engagement with death is increasingly mediated by a series of institutional and professional practices. ${ }^{2} \mathrm{We}$ encounter physical death in predictable ways: through end-oflife care, memorials, and cemeteries. While physical death remains sequestered, our engagement

\footnotetext{
${ }^{1}$ See for example: Odom et al. "Technology heirlooms?: considerations for passing down and inheriting digital materials." In Proceedings of the SIGCHI Conference on Human Factors in computing systems, pp. 337-346. ACM, 2012; Massimi, Michael, Will Odom, David Kirk, and Richard Banks. "HCl at the end of life: understanding death, dying, and the digital." In CHI'10 Extended Abstracts on Human Factors in Computing Systems, pp. 4477-4480. ACM, 2010; Hopkins, Jamie Patrick, and Ilya A. Lipin. "Viable solutions to the digital estate planning dilemma." Iowa Law Review Bulletin 99 (2014): 61; McCallig, Damien. "Facebook after death: an evolving policy in a social network." International Journal of Law and Information Technology 22, no. 2 (2014): 107-140; Stokes, Patrick. "Deletion as second death: the moral status of digital remains." Ethics and Information Technology 17, no. 4 (2015): 237-248.

${ }^{2}$ Smith, Warren. "Organizing death: Remembrance and re-collection." Organization 13, no. 2 (2006): $225-244$.
} 
with the dead is now ever-present. Through their digital estates, the dead are as close to us as they were prior to sequesterization.

Digital estates are dual natured as both memory objects and mourning sites. Memory objects are items passed down through generations: jewelry, tools, furniture, and other traditional heirlooms 'hold' a record of previous use. For example, the peculiar shape of an earring back, the acquired, aged form of leather goods, or the comfort of linen washed countless times; these record and make accessible for us both memories and particular 'knowledge' tied to the inheriting of such objects. ${ }^{3}$ We hold a fine embroidered square and remember a family member's passing, but also recall their instruction on the stitching, and the complexities of our interpersonal relationship. A site of mourning can be an altar, cemetery, monument, or other memorial area. ${ }^{4}$ Digital estates have transformed both the object and the site, creating a haunted every-day.

After death the digital estate becomes an active space of grief and memory. Like spontaneous memorials, digital estates allow for "communication about, but directed towards the deceased." 5 Through this memorial communication, the metadata of the self is remixed and ultimately overwritten after death. These practices are now further mediated by technology and our experience of social networks. After the physical body decays, survivors experience a second

\footnotetext{
${ }^{3}$ For in-depth discussion of the physical 'memory' of inherited objects, see Pitsillides, Stacey, Janis Jefferies, and Martin Conreen. "Museum of the self and digital death." Heritage and Social Media: Understanding Heritage in a Participatory Culture (2012): 56.

${ }^{4}$ For example, the analysis of spontaneous, roadside memorials in Everett, Holly J. Roadside crosses in contemporary memorial culture. University of North Texas Press, 2002; or the growing body of literature on the 'ghost bike' memorial phenomena. A digital example which predates the memorialization feature on Facebook are the number of memorial 'groups' and 'pages'.

${ }^{5}$ Pennington, Natalie. "Grieving for a (Facebook) Friend: Understanding The Impact of Social Network Sites and the Remediation of the Grieving Process." Mediating and Remediating Death (2016): 233-250.
} 
loss as digital memory objects are overwritten through memorial communication, and potentially lost through platform changes.

In a single generation, the geography of death and dying moved from the home to institutions. Contemporary death is ever more digital and public, as the same generation which encountered sequestered death embraces new systems of communication. Memories are now mediated through those systems, with relationships continuing and evolving after death as survivors uncover paratexts ${ }^{6}$ of a life. ${ }^{7}$ Contemporary grief involves stratified acts of mourning as the bereaved may discover chat logs, forum posts, blogs, images, emails, music and video, websites crawled by the Internet Archive, projects with bits and bytes decomposing unattended, and various expressions of identity on now deserted content platforms.

As our records move away from analog items and are ever more digital, the 'shoebox' of letters and inherited memory objects become intangible, with heirlooms existing as bits and bytes.

These are no less fragile and in fact may be more so because of cultural conceptions of 'digital'. ${ }^{8}$ Digital estates are not necessarily bequeathed or given an executor, but rather persist online.

Social media allows the living and the dead to exist "through their presence in the experience of others." In particular, platforms like Facebook, Twitter, and Instagram allow us to craft the metadata of the self in thoughtful ways, a curated exhibition of artifacts of the self to others. Though some scholars argue our digital remains are more permanent and stable than a corpse, I

\footnotetext{
${ }^{6}$ I use paratext to describe memorial communication toward the deceased as part of their digital estate, for example the posting of goodbye messages or other expressions of grief within a particular platform. These are not necessarily a part of the original estate.

${ }^{7}$ Consider the once common practice of saving an answering machine message tape or voicemail recording.

${ }^{8}$ Fox, Robert. "Forensics of digital librarianship." OCLC Systems \& Services: International digital library perspectives 27, no. 4 (2011): 264-271.

${ }^{9}$ Stokes, Patrick. "Deletion as second death: the moral status of digital remains." Ethics and Information Technology 17, no. 4 (2015): 237-248. (Stokes 238)
} 
suggest this is not the case because of how digital estates manifest in social media. By interacting with people who've passed away, the gestures of self we choose while alive are overwritten with time, moving beyond intended representations. Our relationships with the dead change through our interactions with the estate, and as a result our memories are "subject to ongoing revision." 10

Social media is far from the first technology to complicate death. Early photography embraced memento mori as exposure times made living subjects difficult to capture in focus. Postmortem photography focused Victorian mourning ritual into the first widely available memory objects to offer an accurate representation of the dead.

Such images were "commonplace in the nineteenth century, where death occurred in the home and was an ordinary part of life."11 Today, instead of losing entire branches of families to tuberculosis, influenza, or cholera, death is accessible whenever we check our social media feeds. After we die, someone somewhere "curates bits against our ruins." ${ }^{12}$ When the living engage a digital estate, they encounter its lossy quality, its private grounds and open architectures, its inherent composite state as those interactions overwrite intention and become spaces for survivors to grieve. Physical death may be removed from our everyday experience, but we carry graveyards in our phones. There is a "common syntax of grief" ${ }^{\prime 3}$ where librarians and information professionals can intervene.

\footnotetext{
${ }^{10}$ Bennett, Jeffrey, and Jenny Huberman. "From monuments to megapixels: Death, memory, and symbolic immortality in the contemporary United States." Anthropological Theory 15, no. 3 (2015): 338-357.

${ }^{11}$ Hirsch, Robert. Seizing the light: A history of photography (2008), 33.

12 Nowviskie, Bethany. "Digital humanities in the Anthropocene." Digital Scholarship in the Humanities (2015): fqv015.

${ }^{13}$ Cann, Candi K. "Tweeting death, posting photos, and pinning memorials: Remembering the dead in bits and pieces." Digital Death: Mortality and Beyond in the Online Age. Santa Barbara, CA: Praeger (2014): 69-82. Pg 69
} 


\section{Death as Spectacle}

The contemporary experience of death is morphing into spectacle, particularly for the extrajudicial killing of Black people at the hands of the state. ${ }^{14}$ In these cases, intention and representations of self via the digital estate shift immediately; e.g, the viral circulation of a photo of Trayvon Martin at an aviation program in response to media outlets portraying him as a criminal, or the many creative works depicting Martin distributed over social media networks. ${ }^{15}$ Martin's public digital estate is further complicated by postmortem defacement from a white supremacist. ${ }^{16}$ Michael Brown's digital estate was utilized in similar ways, as supporters distributed his high school graduation picture and images of his anguished father as narrative correction. ${ }^{17}$

Death as spectacle acknowledges that all images are funerary. In engaging those estates, their deaths are transformed and public grief through social media becomes an act of solidarity. ${ }^{18}$ For those estates-turned-spectacle, information professionals must be cautious and deliberate in their work to preserve the digital footprints of and about the deceased. In these cases, "spectacle swallows whole the story and spits back little to interrogate." ${ }^{19}$ Working with these estates will involve great care and verification to determine the origins of individual objects, as well as

\footnotetext{
${ }^{14}$ Noble, Safiya Umoja. "Teaching Trayvon: Race, media, and the politics of spectacle." The Black Scholar 44, no. 1 (2014): 12-29.

${ }^{15} \mathrm{Ibid}, 13$. Coverage was so widespread that two images surface as visual shorthand for the event itself: Black people wearing hoodies to challenge the narrative Martin was inherently threatening, and Skittles candy with Arizona tea, the items Martin purchased from a convenience store before his death.

${ }^{16}$ Ebony Magazine, http://www.ebony.com/news-views/white-supremacist-hacks-trayvon-martinsemail\#axzz2ez1v2e83

${ }^{17}$ See the coverage of Emmitt Till's death for an example of this predating social media. Much like the Martin and Brown families sought to create a more 'whole story' of their children, Till's mother deliberately showed the brutality of her son's death.

${ }^{18}$ Cann, Candi K. "Tweeting death, posting photos, and pinning memorials: Remembering the dead in bits and pieces." Digital Death: Mortality and Beyond in the Online Age. Santa Barbara, CA: Praeger (2014): 69-82. Pg 71

${ }^{19}$ Noble, 14
} 
identifying the assemblages and production of "mediated witnessing." ${ }^{20}$ In these cases, art and other objects created for the deceased may be of equal importance to the estate itself for the bereaved. Although this topic is covered by other scholars, information professionals must consider how they will address patrons engaging these estates, and how the library itself might engage in possible acts of correction, collection, and mourning.

\section{Collecting Loss}

\section{Social Media and Websites}

Memorial websites appeared in the United States during the mid-1990s. ${ }^{21}$ However, use of social media for this purpose was not widely recognized until the 2007 Virginia Tech shooting, when university communities took to Facebook to process their grief.

Platform policy changes further complicate grief: Twitter now allows people to see their full private message history, previously limited to the last one hundred messages. After installing Facebook's mobile apps, some users report receiving unread messages from dead friends.

In her account of a friend's death mediated through Facebook, Julie Buntin expresses a desire to locate her grief in the known and accessible, lamenting: "The Internet has complicated the question of where to store my loss. How can I move on, if Lea's face is always lurking in my

\footnotetext{
${ }^{20}$ Papailias, Penelope. "Witnessing in the age of the database: Viral memorials, affective publics, and the assemblage of mourning." Memory Studies 9, no. 4 (2016): 437-454.

${ }^{21}$ Haverinen, Anna. "Memoria virtualis-death and mourning rituals in online environments." (2014).
} 
phone... With every Facebook upgrade it seems like the platform makes it easier for me to become an archeologist of Lea's past." 22

Buntin's question about storing loss has multiple meanings here and is an expression of her desire to assign a place to Lea's memory, to locate her anguish in the known and accessible. Buntin's longing to store her loss is a wish for a memorial space or possession, a "guarantee of the presence of the absent other." 23 Unlike memory objects passed down through generations, digital lives are not consolidated in known spaces. They are scattered throughout different software, mediated through multiple expressions of self through various platforms. These range from the mundane, but new arenas of loss for the living to negotiate-automatic bill pay systems, rewards programs - to the spaces between a LinkedIn profile and a throwaway Reddit account. Together they are kaleidoscopic metadata, a composite self that the digital allows us to affirm, attenuate, and — with great effort—-destroy.

While Buntin refrained from overwriting her friend's digital estate, she observed others do so as the space shifted from one of production to stillness. Perhaps the most remarkable thing about the dead online is their relative quiet compared to the hundreds of messages our networks produce in a day. Those connected to the deceased fill that silence with memorial communication. Digital estates are restless, haunting the everyday. A web developer for an academic library writes about the paradox of public and private grief: "I've learned that the hardest part about losing someone 'digitally' close to you, is that the physically present folks

\footnotetext{
22 Buntin, Julie. "She's Still Dying On Facebook." The Atlantic (2014): http://www.theatlantic.com/technology/archive/2014/07/shes-still-dying-on-facebook/373904/ ${ }^{23}$ For more on this concept, see Stewart, Susan. On longing: Narratives of the miniature, the gigantic, the souvenir, the collection. Duke University Press, 1984. Applied to the digital, see Giaccardi, Elisa. Heritage and social media: Understanding heritage in a participatory culture. Routledge, 2012.
} 
around you have no idea why you are upset. They can't grieve with you or feel empathy, because they don't 'get it.' My loss is invisible, yet my loss is just as devastating."24

\section{Gaming}

Repurposing technology to process grief is not unique to social media. Players have extended these practices into virtual realms since their inception, with Multi-User Dungeons (MUD) holding text-based funerals for dead players as early as the 1970 s. ${ }^{25}$ Funerals and memorials for dead players are common to most Massively Multiplayer Online Games (MMOGs).

Sometimes in-game memorials are significant enough to draw attention from outside the game's community, as was the case with EVEOnline in 2012. Following the U.S. consulate attack in Libya, thousands of players memorialized Sean Smith, a Foreign Service officer killed in the attack, who they knew as famous diplomat Vile Rat. Vile Rat's obituary appeared in Harper's Magazine and Huffington Post. Both highlighted his role with the consulate and his life as an avid gamer.

In addition to screenshots and recorded game play, survivors collect chat logs, emails, and game artifacts to remember deceased players. When players die, the bereaved should consider gaming avatars to be extensions and augmentations of the self, and should therefore be treated with the same level of attention and care.

\footnotetext{
${ }^{24}$ Leah Root, e-mail message to author, October 30, 2016.

${ }^{25}$ Kelly, Kevin, and Howard Rheingold. "The dragon ate my homework." (1993): 69.
} 


\section{Taking Inventory}

Information professionals can conduct a reference interview to see which of the starting points offered in the appendix may be available to the bereaved, with the caveat that these are offered as entry points to generate conversation and should not be seen as exhaustive. As these reference interviews may be more intense than usual, maintaining distance without appearing clinical is important. Patrons will have varying degrees of comfort with technology, and defining what they believe is meaningful to the digital estate will determine the scope of the assistance we can provide. We have no power over how others will mourn, nor over what they find significant during the investigation of an estate.

To keep interactions manageable, information professionals can borrow from the Library of Congress' guidelines for personal digital archiving for the living: ${ }^{26}$

1. Identify what potentially exists in the digital estate. Patrons may return to this stage of discovery throughout their grieving process as new objects are found.

2. Define the scope of the interaction and maintain those boundaries throughout.

3. Determine what can be accessed for preservation.

4. Decide which objects are meaningful.

5. Save the objects.

6. Describe the objects in a useful way: 00001.jpg is less helpful. SmithGraduation.jpg is more helpful.

7. Make copies. If patrons choose to upload them to a storage service, they should consider granting access to more than one person.

\footnotetext{
${ }^{26}$ These steps are adapted from the Library of Congress' digital preservation and personal archiving of websites guidelines. http://www.digitalpreservation.gov/personalarchiving/websites.html
} 
Together, a primary email account and current cell phone are the best tools available for mapping a digital estate. Deceased persons with an interest in security potentially enabled two factor authentication. In these cases our ability to see an estate more fully relies on access to both email and a cell phone.

In the absence of these tools, we can still assist the recovery of other significant objects. Converting from one format to another-reformatting a VHS tape, for example —is usually outside the scope of the estate but public libraries and the Library of Congress' Personal Digital Archiving resources can be helpful here.

Librarians and information professionals working in any capacity with digital estates must be prepared to refer patrons to additional resources within and outside the library, depending on the nature of information uncovered as a result of exploring a digital estate.

A survivor's loss can be mediated through vast estates of multiple personas, identity performances, platforms, and objects. These manifest in a variety of ways:

- A transwoman is out to her community and family of choice but estranged from her family of origin at the time of her death.

- The scholar who changes their surname throughout their career. They maintain distinct professional, public, and private identities. They may or may not have a unique identifier linking their professional works, such as ORCID.

- A young woman who adopted her childhood nickname as an adult because no one in her elementary school could pronounce her legal name. 
These scenarios and their endless variations hold clues to identifying the user's estate.

Usernames may be re-used in certain contexts. We may have a username we consistently use for our professional identity (smith85), another for our personal interests (smith_loves_bikes), and still others for platforms where usernames communicate information about us explicitly, like dating apps (stillseeking85).

In searching for these accounts, there may be links between platforms and identity performance in particular if a 'throwaway' or 'anonymous' account is uncovered. These accounts are in some ways misnamed - throwaway suggests an easily discarded portion of the self, a peripheral piece of representation. On Reddit for example, it's trivial to create throwaway accounts for information seeking and confessional use. To throw away those comments is a deliberate attempt to disassociate from the primary digital estate because of their often profound personal nature. When patrons ask how to recovery 'everything' we need to educate patrons on what everything might mean.

\section{Legal Issues and Access}

Limited attempts to address the lack of for protocol digital estate management exist. The Digital Beyond list several dozen posthumous data and digital heirloom services. The majority of these services were founded after 2007 and none appear to have data sharing agreements or interoperability standards. A brief review showed no metadata standards between services, a foundational component of digital preservation. ${ }^{27}$ Preserved objects without metadata cannot be discovered without considerable intervention. Such objects run the risk becoming massive, hidden collections of the dead, assuming these estates survive at all.

\footnotetext{
${ }^{27}$ See thedigitalbeyond.com/online-services-list/
} 
Gaining access through Google's Inactive Account Manager is one solution, but not everyone uses Gmail accounts. Email can provide a vital access point, but is not the whole of a digital estate. Lack of policy addressing death on the part of many providers is a growing problem. ${ }^{28}$ Although early research on digital estates predates the linking of YouTube, Picasa, Drive, Gmail and other Google products to a single identity in 2013, the issues of access and inheritance of digital estates remains problematic.

In 2005, Yahoo! was compelled by a court ruling to provide the family of Justin Ellsworth, a United States Marine killed in Iraq, with his email records. Yahoo! still maintains terms of service that do not permit transference or access. ${ }^{29}$ Facebook fielded several controversial cases before and after instituting their memorial policy, one concluding after a two-year court case ${ }^{30}$, and another after court orders were issued to Facebook and Google for parents to gain access over a diseased child's digital estate. ${ }^{31}$

Five states have passed laws to assist digital estate management: Connecticut, Idaho, Oklahoma, Rhode Island, and Indiana. Several other states have legislation pending.

\section{Emerging Roles and Services}

The frequency of legal action against providers suggests the needs of survivors are not addressed through profile memorialization alone and that many are not aware of Google's Inactive Account

\footnotetext{
${ }^{28}$ Wiley, Cyndi, Yun Wang, Ryan Musselman, and Beverly Krumm. "Connecting Generations: Preserving Memories with Thanatosensitive Technologies." In International Conference on Human-Computer Interaction, pp. 474-478. Springer Berlin Heidelberg, 2011.

${ }^{29}$ See Yahoo!'s terms of service here: info.yahoo.com/legal/us/yahoo/utos/utos-173.html

${ }^{30}$ Avok, M. (2013 10-1). Karen Williams' Facebook Saga Raises Question of Whether Users' Profiles are part of "Digital Estates." Retrieved from http://www.huffingtonpost.com/2012/03/15/karen-williamsfacebook_n_1349128.html.

${ }^{31}$ Epstein, E. A. (2013, June 6-13). Family Fights to Access Son's Facebook Account after his Suicide. The Daily Mail. Retrieved from http://www.dailymail.co.uk/news/iirticle2153548/Family-ñghts-access-sons-Facebook-Gmailaccounts-suicide.html.
} 
Manager. This is unsurprising, given the number of people without end-of-life care plans, advanced directives, and living wills. ${ }^{32}$

Perhaps the most important part of acknowledging the information professional's role is that it allows the bereaved to locate themselves in a future possible, where estates are discoverable and grief consented to, not a series of random, disruptive encounters. Because this kind of work involves a high level of emotional labor for professionals with service centered orientations, the library must decide the scope and investment they are willing to commit to these kinds of questions and services.

Library patrons have the opportunity to see the files they create as part of a greater cultural narrative; this is one of the talking points the District of Columbia Public Library offers for its Memory Lab. This allows information professionals to frame events and services in the context of producing a relevant part of cultural history rather than death.

Conversely, the death-positive movement and its various incarnations can offer guidance for how to initiate often difficult conversations about death and dying in the context of the library or similarly positioned host institution. Indeed, because death and dying affects everyone, the opportunities for information professionals who might not otherwise collaborate are exceptional. Unexplored collaborations between departments, experts, and the community are possible within the tensions offered by digital estates. Information professionals have countless avenues to explore connecting project management, inheritance and benefits, preservation, technology education through enabling the creation of digital memorial objects for survivors, maintenance of

\footnotetext{
32 Rao, Jaya K., Lynda A. Anderson, Feng-Chang Lin, and Jeffrey P. Laux. "Completion of advance directives among US consumers." American journal of preventive medicine 46, no. 1 (2014): 65-70.
} 
digital estates for the living, and the justice work implicit in narrative correction, holding space for mourning, or archiving those digital estates.

\section{Appendix: Starting Points for Reference Interviews and Mapping Digital Estates}

Physical components of the digital estate

- Current and old cell phones ${ }^{33}$

- SD cards

- Portable storage like USB memory and zip drives

- Tablets

- eReaders

- Laptop and desktop computers

- Cameras

\section{Task-based components}

- Password managers

- Calendars

- Automatic withdraws from primary banking accounts

- Direct deposits

- Tax information

- Insurance policies

\section{Digital components}

- Usernames and other potential unique identifiers

- Photos, video, audio - both saved and created by the deceased user

- Streaming media accounts

- Text messages and voice mail

- Activity through apps

- Social media presence

- Blogs

- Avatars/player characters in virtual environments

- Communication directed to or about the deceased. 


\section{Selected Bibliography}

Bennett, Jeffrey, and Jenny Huberman. "From monuments to megapixels: Death, memory, and symbolic immortality in the contemporary United States." Anthropological Theory 15, no. 3 (2015): 338-357.

Buntin, Julie. "She's Still Dying On Facebook." The Atlantic (2014): http://www.theatlantic.com/technology/archive/2014/07/shes-still-dying-onfacebook/373904/

Cann, Candi K. "Tweeting death, posting photos, and pinning memorials: Remembering the dead in bits and pieces." Digital Death: Mortality and Beyond in the Online Age. Santa Barbara, CA: Praeger (2014): 69-82.

Costello, Matthew W. "The 'PEAC' of digital estate legislation in the United States: should states 'like' that?" Suffolk University Law Review, Summer 2016.

Dougherty, William C. "Preservation of digital assets: One approach." The Journal of Academic Librarianship 35, no. 6 (2009): 599-602.

Frank, Jeffrey. "The impact of hurricane Katrina on Gulf Coast libraries and their disaster planning." (2011).

Hopkins, Jamie Patrick, and Ilya A. Lipin. "Viable solutions to the digital estate planning dilemma." Iowa Law Review Bulletin 99 (2014): 61.

Kelly, Kevin, and Howard Rheingold. "The dragon ate my homework." (1993): 69.

Lingle, Virginia A., and Dorothy L. Malcom. "Interlibrary loan management with microcomputers: a descriptive comparison of software." Medical reference services quarterly 8, no. 2 (1989): 41-64.

Massimi, Michael, and Andrea Charise. "Dying, death, and mortality: towards thanatosensitivity in HCI." In CHI'09 Extended Abstracts on Human Factors in Computing Systems, pp. 2459-2468. ACM, 2009.

Massimi, Michael, Will Odom, David Kirk, and Richard Banks. "HCI at the end of life: understanding death, dying, and the digital." In CHI'10 Extended Abstracts on Human Factors in Computing Systems, pp. 4477-4480. ACM, 2010.

McCallig, Damien. "Facebook after death: an evolving policy in a social network." International Journal of Law and Information Technology 22, no. 2 (2014): 107-140.

Notess, Greg. "Surviving Rot and Finding the Online Past." Online Searcher 38(2): 65-67, Mar/Apr 2014.

Nowviskie, Bethany. "Digital humanities in the Anthropocene." Digital Scholarship in the Humanities (2015): fqv015. 
Odom, William et al., "Technology heirlooms?: considerations for passing down and inheriting digital materials." In Proceedings of the SIGCHI Conference on Human Factors in computing systems, pp. 337-346. ACM, 2012.

Papailias, Penelope. "Witnessing in the age of the database: Viral memorials, affective publics, and the assemblage of mourning." Memory Studies 9, no. 4 (2016): 437-454.

Pennington, Natalie. "Grieving for a (Facebook) Friend: Understanding the Impact of Social Network Sites and the Remediation of the Grieving Process." Mediating and Remediating Death (2016): 233-250.

Pitsillides, Stacey, Janis Jefferies, and Martin Conreen. "Museum of the self and digital death." Heritage and Social Media: Understanding Heritage in a Participatory Culture (2012): 56.

Smith, Warren. "Organizing death: Remembrance and re-collection." Organization 13, no. 2 (2006): 225-244.

Stokes, Patrick. "Deletion as second death: the moral status of digital remains." Ethics and Information Technology 17, no. 4 (2015): 237-248.

Weaver, Stephen D., and Mark Gahegan. "Constructing, Visualizing, and Analyzing a Digital Footprint." Geographical Review 97, no. 3 (2007): 324-50. http://www.jstor.org/stable/30034175.

Wiley, C., Wang, Y., Musselman, R., \& Krumm, B. (2011, July). Connecting Generations: Preserving Memories with Thanatosensitive Technologies. In International Conference on Human-Computer Interaction (pp. 474-478). Springer Berlin Heidelberg.

Wright, Nicola. "Death and the Internet: The implications of the digital afterlife" First Monday [Online], Volume 19 Number 6 (21 May 2014) 